\title{
Research on Comprehensive Closing Protection for Capacitor based on ATPIEMTP
}

\author{
He Liu $^{1, \text { a }}$, Hao Zhou ${ }^{1, b}$ \\ ${ }^{1}$ College of Electrical Engineering, Zhejiang University, Hangzhou 310027, China; \\ a635111554@qq.com, bzhouhao_ee@zju.edu.cn
}

Keywords: compensation parallel capacitor group, switch on, phase control synchronous switch, reactor.

\begin{abstract}
Aiming at solving the problem of dash current and over voltage of parallel reactive compensation capacitor group in power system ,this paper research on the phase control synchronous switch and the current-limiting reactor .With the of Huangti system, which involves both of the protection tools, Simulation result demonstrates that dash current and the over voltage would be limited by the corporation of the phase control synchronous switch and the current-limiting reactor.
\end{abstract}

\section{Introduction}

In recent years, with the increase in network capacity, reactive power compensation capacitors are increasingly being used. In order to maintain the stability of system voltage, substation requires frequent switching reactive power compensation capacitors. When inputting capacitors, it will produce flow. Meanwhile, when the inputting capacitor group, there is a transient process. So the capacitor over-voltage is generated. In this paper, using ATP / EMTP simulation software, with the introduction of series reactors and synchronous closing device principle[1,2], uses the Huangti system as an example to simulate and get the result of inputting operation over-voltage and the surge before and after taking protection measures. The simulation results show that both surge current, and the over-voltage can be effectively limited. The simulation results altogether prove the effectiveness of comprehensive protection.

\section{Synchronous Inputting Switch Limiting Over Voltage and Simulation}

\subsection{Synchronous Switching Strategy}

In the capacitor neutral ungrounded system, two capacitors have to bear the line voltage together. Its control strategy is that when the voltage difference between any two phase is zero ,the switch close the capacitors of two phases; because the vector of the difference between the two-phase voltage and the third phase's vector have a difference on a quarter period, the third phase voltage gets zero after the two-phase capacitor's inputting. When the third phase's voltage gets zero, we should put into the third set of capacitors.[5]

\subsection{Huangti transformer substation simulation analysis}

Hangzhou Huangti transformer substation is a $10 \mathrm{kV}$ substation.At the voltage level, parallel compensation capacitor's neutral point is usually ungrounded. Simulation system is shown in Figure 1.The transformer ratio is $110 / 10$.Capacitance is $94.68 \mathrm{uF}$ per phase. System frequency is $50 \mathrm{~Hz}$.Each phase's load impedance is $1 \mathrm{ohm}$.

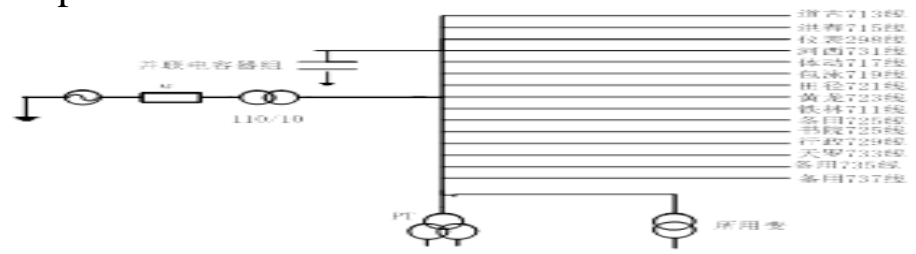

Fig. 1 Huangti simulation system 
Without synchronous switch, when the voltage of phase $\mathrm{A}$ is at the maximum, inputting the capacitor will cause great oscillating voltage. The voltage waveform obtained by the simulation is shown in Figure 2, with the capacitor switch i closed at time 0.

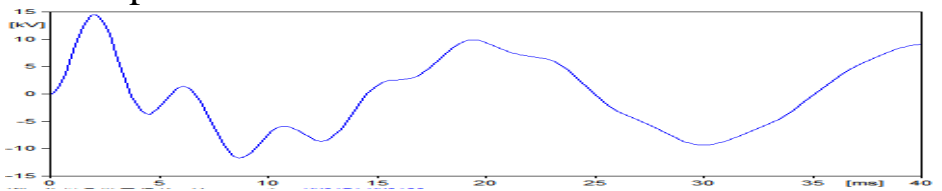

Fig. 2 Over voltage of phase A

When using synchronous switch, A and B phase switch is closed at $0.00333 \mathrm{~s}$, getting the voltage of phase A and B waveform which is shown in Figure 3.

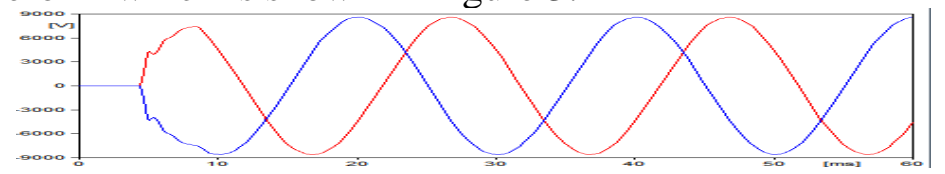

Fig. 3 Over voltage of phase A and B after the access of synchronous switch

Without using synchronous switch, the maximum over-voltage reaches11735V while the steady-state phase voltage is $8593.2 \mathrm{~V}$.Over-voltage is 1.366 times the phase voltage, which proves the system to be effective according to the over-voltage values in common system mentioned before.After using synchronous inputting switch, the maximum oscillation over-voltage is $8599.8 \mathrm{~V}$ with the steady-state phase voltage $8593.2 \mathrm{~V}$.It can be considered to achieve the purpose of over-voltage limiting.

\section{Reactor Limiting Over Current and Simulation}

We continue using Huangti Transformer substation simulation system as example to analysis the surge , which is shown in Figure 1.In the case without using the synchronous closing switch, while $t$ $=0$,the three-phase switch is closed, thus A phase over-voltage gets its maximum. Three-phase inrush current is also the largest, and the inrush current of phase Awaveform is shown in Figure 4.

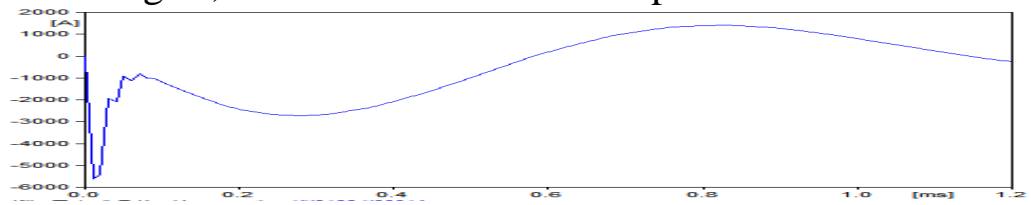

Fig. 4 The inrush current waveform of phase A

Inrush current value reaches nearly 6000A, making the capacitor at threat. We can see that appropriate protective measures must be used to limit inrush current. According to the system's background harmonic, reactors reactance rate of the system is set to 4.5\%.[3][4] Besides the original system, each phase's capacitors is added with reactor of $4.586 \mathrm{mH}$.Still, three-phase switching close time is at the same time set to 0 .The simulation result shows that the A phase inrush current simulation value is the highest one, with the value of 1119.5A.Compared with the original system, surge values are significantly lower so that we can believe that reactors can effectively suppress the harmonics inrush current. After adding the reactors to the system, A phase inrush current simulation waveform is shown in Figure 5.

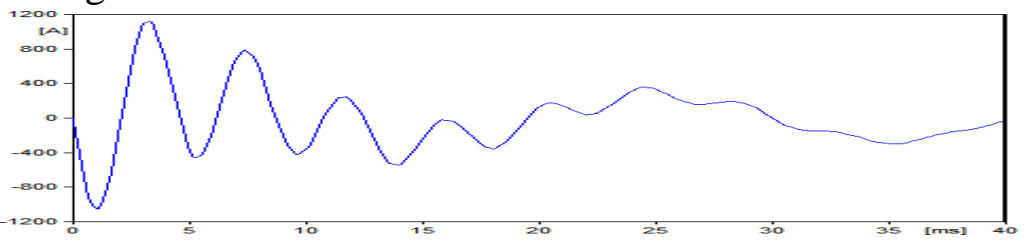

Fig. 5 The inrush current waveform of phase A after adding the reactors 


\section{Simulation of interaction between synchronous closing switch and reactors}

Still using Huangti simulation system shown in Figure 1, we add synchronous closing switch and three-phase reactor whose reactance rate is $5 \%$.When $t=0.00333 \mathrm{~s}, \mathrm{~A}$ and $\mathrm{B}$ phase switches are closed, and $\mathrm{C}$ phase switch is closed when $\mathrm{t}=0.00833 \mathrm{~s}$. Simulation system and condition are described as above ,in which condition we obtains the A, B, C phase voltage waveform shown in Figure 6.

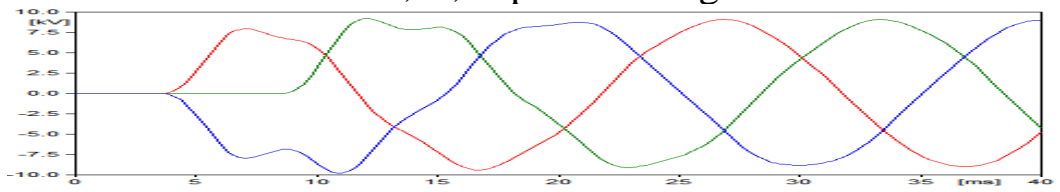

Fig. 6 The over voltage waveform of 3 phases after adding the reactors and the synchronous switch

Comparing Figure 6 and Figure 3, it is clear that, after adding the reactors, the oscillation progress generated by the close of the capacitor's switch is more serious than the system without the reactors and the amplitude of the oscillation over-voltage is also higher with the oscillation time increased. Transition from the oscillation process to the steady-state is longer. The original system reaches the steady-state in 10ms. After the addition of the reactor, the oscillation process continues as long as $20 \mathrm{~ms}$ to reach a basically steady state.

After simulation with the condition mentioned before, we get the three-phase closing impulse current waveform which is shown in Figure 7 .Comparing figure 7with Figure 5, the closing impulse current's peak value decrease from 1119.5A reduced to 429.55A. This value is almost the same as the steady-state current. Thus, using the phase control closing switch not only can effectively reduce the closing over-voltage but also can effectively reduce the inrush current amplitude. Using phase control switch to protect the capacitor can effectively protect capacitors and prevent over-voltage and surge damages.

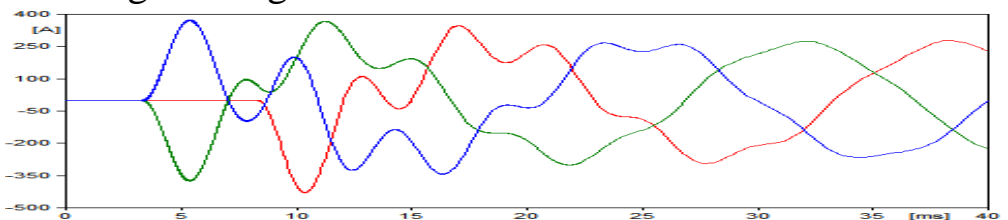

Fig. 7 The three-phase closing impulse current waveform after adding the reactors and the synchronous switch

\section{Impact of Synchronous Closing Switch’s Precision and Simulation}

Synchronous switch over-voltage limit effect and result and phase control switch precision are closely related. The more precise the control switch can get,the smaller the two-phase voltage difference is. So oscillation over-voltage amplitude is smaller if the switch is more precise on time.In [1],switching precision is $0.5 \mathrm{~ms}$, the current closing switches are able to achieve this level of time control precision [6].

Now we take a different synchronous closing precision, except different closing time, all simulation parameters are the same as the system described before with the synchronous closing switch and reactor added to Huangti simulation systems. The relationships between over-voltage result and time precision are shown in Table 1.

Table 1 Three Scheme comparing

\begin{tabular}{llllllllllll} 
Time error & -5 & -4 & -3 & -2 & -1 & 0 & 1 & 2 & 3 & 4 & 5 \\
\hline Over voltage times & 1.45 & 1.24 & 1.21 & 1.07 & 0.98 & 0.94 & 1.07 & 1.32 & 1.49 & 1.54 & 1.45
\end{tabular}

According to Table 1, when the time control switch precision isless than 1ms, synchronous closing switch can effectively control the closing capacitor. When time control error is over $1 \mathrm{~ms}$, due to the two-phase voltage difference's increase, the transition process resulted in more serious 
oscillation progress and higher over-voltage amplitude. When the time control switch error is more than 3ms, the over-voltage amplitude is even higher than system without synchronous closing switch. Therefore, the closing time precision must be strictly controlled. When synchronization error is within $1 \mathrm{~ms}$, the closing over-voltage is an acceptable value.

\section{Summary}

In this paper, we proposed to add the corresponding reactor and synchronous closing switches. By comparison with the original value and the corresponding value of over-voltage and surge by simulation after adding synchronous closing switch and the reactors, it is believable that synchronous closing switch can effectively limit the over-voltage, and that reactors can effectively limit the inrush current. To further confirm that the protect measures will not interfere with each other, which would resulti in protection failure, in the system with both protection added to Huangti system we make the simulation again and the result is that the protect measures can still effectively limit both overvoltage and the closing inrush current, proving the effectiveness of comprehensive protection. At last, we research on the impact of the error of synchronous closing device on over-voltage protection. Comprehensive analysis showed that synchronous closing switch is able to effectively protect the closing capacitor when meeting the requirements on the time error.

\section{References}

[1].Duan Xiongying,Zou Jiyan,Fang Chunen,et al.Synchronized control tactics of phasing vacuum switches when closing capacitor banks.Journal of Dalian university of technlogy .Vol.43(2008)No.4,p457-460.

[2].Zhong Hao,Hu Renjie.A synchronous switching device for reactive power compensation capacitor based on closed-loop current control.Power System Protection and Control. Vol.40(2012)No.6.p129-146.

[3].Maliang,Qian Loujiang. Impact of harmonics on the internal fault protections of assembling capacitor.POWER SYSTEM PROTECTION AND CONTROL.Vol.38(2010)No.15,p.87-90.

[4].CHEN Bo-sheng.HARMONICS RESTRAINING FUNCTIONN OF SERIAL REACTOR AND SELECTION OF REACTANCE RATE.Power System Technology.Vol.27(2003)No.12,p92-95.

[5].Fang Chun'en,Wang Jiaying,Zou Jiyan.The Investigation on Optimal Making Phase for Synchronous Closing Shunt Capacitor Banks.TRANSACTIONS OF CHINA ELECTROTECHNICAL SOCIETY.Vol.21(2006)No.1,p.24-27.

[6].YAN Xianglian,LI Zhibing ,WANG Chengyu.Analysis on Characteristics of Phase-Selectable Circuit Breaker for Switching Capacitor Banks in UHV Power Transmission Project.Power System Technology. Vol.38(2014)No.7,p.1772-1778 